\title{
WP 15-12
}

\author{
Luca Lambertini
}

Department of Economics, University of Bologna, Italy

The Rimini Centre for Economic Analysis, Italy

Raimondello Orsini

Department of Economics, University of Bologna, Italy

\section{QUALITY IMPROVEMENT AND PROCESS INNOVATION IN MONOPOLY: A DYNAMIC ANALYSIS}

Copyright belongs to the author. Small sections of the text, not exceeding three paragraphs, can be used provided proper acknowledgement is given.

The Rimini Centre for Economic Analysis (RCEA) was established in March 2007. RCEA is a private, nonprofit organization dedicated to independent research in Applied and Theoretical Economics and related fields. RCEA organizes seminars and workshops, sponsors a general interest journal The Review of Economic Analysis, and organizes a biennial conference: The Rimini Conference in Economics and Finance (RCEF) . The RCEA has a Canadian branch: The Rimini Centre for Economic Analysis in Canada (RCEACanada). Scientific work contributed by the RCEA Scholars is published in the RCEA Working Papers and Professional Report series.

The views expressed in this paper are those of the authors. No responsibility for them should be attributed to the Rimini Centre for Economic Analysis. 


\title{
Quality Improvement and Process Innovation in Monopoly: A Dynamic Analysis*
}

\author{
Luca Lambertini $\#, \S$ and Raimondello Orsini $\#$ \\ \# Department of Economics, University of Bologna \\ Strada Maggiore 45, 40125 Bologna, Italy \\ luca.lambertini@unibo.it \\ raimondello orsini@unibo.it \\ $\S$ RCEA, via Patara 3, 47900 Rimini, Italy
}

March 12, 2015

\begin{abstract}
We investigate the R\&D portfolio of a monopolist investing in costreducing and quality enhancing $R \& D$. Incentives along the two directions are inversely related to the size of market demand, and independent of each other. The stability analysis shows the existence of a unique stable steady state equilibrium, which is a saddle point. Finally, we show that the monopolist undersupplies product quality as compared to the social optimum, while its investment in the abatement of marginal cost is socially efficient.
\end{abstract}

Keywords: product innovation, cost reduction, R\&D portfolio.

JEL Codes: L12, O31

*We would like to thank Andrea Mantovani and Arsen Palestini for precious comments and suggestions. The usual disclaimer applies. 


\section{Introduction}

The impact of monopoly power on product quality is a vexata quaestio in the theory of industrial organization, at least since Spence (1975) and Mussa and Rosen (1978), where the main issue under investigation is the firm's tendency to distort quality downwards to extract as much surplus as possible from consumers' pockets. ${ }^{1}$ This literature, however, (i) is based on static models, and therefore by construction falls short of characterising the inherently dynamic nature of quality improvement; (ii) leaves out of the picture any other form of investments, such as any effort directed at decreasing marginal production costs, and finally (iii) disregards advertising activities (either persuasive or informative) aimed at increasing demand or making the product more appealing to consumers and thus convince them to pay higher prices for it.

Here, we propose a model addressing aspects (i) and (ii), leaving aside (iii), which has generated a lively debate since the late 1970s, stemming from the pioneering contribution of Kotowitz and Mathewson (1979). ${ }^{2}$ We characterise the optimal $\mathrm{R} \& \mathrm{D}$ portfolio of a monopolist investing in costreducing and quality improving activities under full market coverage, and selling its product to a population of consumers endowed with different levels of willingness to pay for quality. Our results can be summarised as follows.

First, observing the control equations describing the evolution of the two R\&D efforts over time, it can be established that a larger demand size exerts a negative effect on both innovation rates at any time. Second, we find that, at any time, the two innovation efforts are independent of each other, due to the assumption of full market coverage. This is in striking contrast to the extant literature on R\&D portfolios, where either complementarity or substitutability between product innovation and cost reduction usually arises. ${ }^{3}$ Third, we prove that there exists a multiplicity of steady state points, among

\footnotetext{
${ }^{1}$ This aspect has been largely debated: see Itoh (1983), Maskin and Riley (1984), Besanko, Donnenfeld and White (1987), Champsaur and Rochet (1989), Lambertini and Orsini (2000) and Lambertini (2006), among others.

${ }^{2}$ The bulk of the resulting literature is summarised in Feichtinger et al. (1994). For a later contribution in this vein, see Colombo and Lambertini (2003).

${ }^{3}$ The simultaneous presence of product and process innovations and their relation to product life cycle in monopoly and oligopoly models is in Lambertini and Mantovani (2009, 2010), using the representative consumer approach (Singh and Vives, 1984), which generates a price-elastic market demand. In these models, product and process R\&D efforts may be either complements or substitutes and their relative intensity depends on initial conditions and demand parameters.
} 
which a unique stable equilibrium can be singled out, this being a saddle point solution. The stability analysis is carried on a Jacobian matrix which is a block diagonal one, the latter property being due to the aforementioned fact that the two dimensions of innovation are independent of each other. Fourth, the welfare assessment reveals that the profit-maximising monopolist disorts quality downwards as compared to the social optimum, while producing the socially efficient effort along the process innovation dimension.

The remainder of the paper is structured as follows. The setup in in Section. The equilibrium analysis is in Section 3, while Section 4 contains the stability analysis. Section 5 examines the welfare implications. Concluding remarks are in Section 6.

\section{The model}

Our model is a variation on the setup introduced by Mussa and Rosen (1978) and Gabszewicz and Thisse (1979). We assume the market is supplied by a single-product monopoly selling a nondurable good of quality $q(t)>0$ at price $p(t)>0$ over continuous time $t \in[0, \infty)$. The population of consumers is characterised by a level of marginal willingness to pay for quality $\theta \in$ $[\Theta-1, \Theta]$, where $\Theta>1$, and is distributed with a uniform density $d$ over such interval. Hence, the total mass of consumers amounts to $d \geq 1$. Parameter $\theta$ can be interpreted as a proxy of income or wealth. ${ }^{4}$ At any time $t \in[0, \infty)$, full market coverage is assumed, with each individual buying a single unit of the good, ${ }^{5}$ whereby his net surplus is

$$
U=\theta q(t)-p(t) \geq 0 .
$$

Production takes place at marginal cost $c(t)$, which can be decreased (generating thus what is usually defined as process innovation) via an R\&D effort $y(t)$. The monopolist also invests in product innovation (or quality improvement) via the effort $k(t)$, to increase $q(t)$. The total cost function borne by

\footnotetext{
${ }^{4} \mathrm{~A}$ similar although not entirely equivalent and less frequent approach consists in modelling consumer preferences by describing explicitly their income distribution. See Shaked and Sutton (1982), inter alia.

${ }^{5}$ Full market coverage may be interpreted as describing a situation in which demand size is known a priori because under full information the firm may identify at the outset the position $\Theta-\alpha$ of the marginal consumer. Here, for simplicity and through an appropriate choice of measure, $\alpha=1$.
} 
the firm is ${ }^{6}$

$$
C(t)=c(t) x(t)+b k^{2}(t)+s y^{2}(t)+v q^{2}(t)
$$

where $x(t)$ is output, while $b, s$ and $v$ are positive parameters. The term $v q^{2}(t)$ in (2) measures the instantaneous cost of producing a quality level $q(t)$ using machinery and/or skilled labour operating at decreasing returns. The state dynamics describing the evolution of $c(t)$ and $q(t)$ over time are

$$
\begin{gathered}
\frac{d q(t)}{d t} \equiv \dot{q}=[k(t)-\delta] q(t) \\
\frac{d c(t)}{d t} \equiv \dot{c}=-[y(t)-\eta] c(t)
\end{gathered}
$$

in which $\delta>0$ is the decay rate of quality while $\eta>0$ is the obsolescence rate affecting production technology. ${ }^{7}$

Under full market coverage, $x(t)=d$ and the profit-maximising price extracts the entire surplus from the pockets of the poorest consumer, i.e., it is $p^{m}(t)=(\Theta-1) q(t)$, with superscript $m$ standing for monopoly (cf. Lambertini, 1997, p. 113). The monopolist's instantaneous profits are

$$
\pi(t)=[(\Theta-1) q(t)-c(t)] d-b k^{2}(t)-s y^{2}(t)-v q^{2}(t)
$$

and the firm wants to maximise the discounted profit flow

$$
\Pi(t)=\int_{0}^{\infty} \pi(t) e^{-\rho t} d t
$$

w.r.t. controls $k(t)$ and $y(t)$, under the constraints posed by the state equations (3-4), initial conditions $q(0)=q_{0}>0, c(0)=c_{0} \in(0,(\Theta-1) q(0))$, and the appropriate transversality conditions to be specified below. It is worth observing that the initial condition on marginal cost says that it must be strictly lower than the spending capability of the poorest consumer existing in this market, in order for full market coverage to hold at $t=0$. Profits are discounted at the constant rate $\rho>0$.

\footnotetext{
${ }^{6}$ We are assuming that the entire $R \& D$ activity is carried out in house by the integrated firm. For an assessment of the bearings of outsourcing on quality improvement, and the related contractual design, see El Ouardighi and Kim (2010) and El Ouardighi and Kogan (2013), inter alia.

${ }^{7}$ We are supposing that $\mathrm{R} \& \mathrm{D}$ has an immediate impact, which is admittedly a simplifying and unrealistic assumption which, however, is commonly adopted.
} 


\section{$3 \quad$ Equilibrium analysis}

The firm's current value Hamiltonian is ${ }^{8}$

$$
\mathcal{H}=e^{-\rho t}(\pi+\lambda \dot{q}+\mu \dot{c})
$$

where $\lambda=\zeta e^{\rho t}$ and $\mu=\psi e^{\rho t}$ are the costate variables (evaluated at time $t$ ) associated with $q$ and $c$, respectively. The resulting first order conditions (FOCs) on controls and costate equations are (exponential discounting is omitted for brevity):

$$
\begin{gathered}
\frac{\partial \mathcal{H}}{\partial k}=-2 b k+\lambda q=0 \\
\frac{\partial \mathcal{H}}{\partial y}=-2 s y-\mu c=0 \\
\dot{\lambda}=-\frac{\partial \mathcal{H}}{\partial q}+\rho \lambda \Leftrightarrow \\
\dot{\lambda}=(\delta+\rho-k) \lambda-d(\Theta-1)+2 h q \\
\dot{\mu}=-\frac{\partial \mathcal{H}}{\partial c}+\rho \mu \Leftrightarrow \\
\dot{\mu}=(\rho-\eta+y) \mu+d .
\end{gathered}
$$

The accompanying set of transversality conditions is $\lim _{t \rightarrow \infty} \lambda q e^{-\rho t}=0$ and $\lim _{t \rightarrow \infty} \mu c e^{-\rho t}=0$.

From (8-9), we have the optimal controls at time $t$ :

$$
k^{*}=\max \left\{0, \frac{\lambda q}{2 b}\right\} ; y^{*}=\max \left\{0,-\frac{\mu c}{2 s}\right\}
$$

and the control equations

$$
\dot{k}=\frac{\dot{\lambda} q+\lambda \dot{q}}{2 b} ; \dot{y}=-\frac{\dot{\mu} c+\mu \dot{c}}{2 s}
$$

which, using (8-9) and (12), can be rewritten as follows:

$$
\dot{k}=\rho k-\frac{q[(\Theta-1) d-2 v q]}{2 b}
$$

\footnotetext{
${ }^{8}$ Henceforth, we shall omit the explicit indication of the time argument for the sake of brevity.
} 


$$
\dot{y}=\rho y-\frac{c d}{2 s}
$$

The system composed by (3-4) and (14-15) identifies the state-control system of the dynamic problem at hand. In particular, the above control equations show that the instantaneous R\&D rates in both directions is decreasing in the density parameter $d$. Given that $d$ in this model also measures the total mass of consumers, we may formulate:

Lemma 1 The instantaneous investment rates in product and process innovation are inversely related to the size of demand.

The above Lemma captures a perverse effect of mass consumption on technical progress which is often confirmed by casual observation, namely, that expanding demand jeopardises a firm's incentives to increase the built-in quality or technological content of a given product. The reason can be found in the fact that a larger demand basin ensures at no cost higher revenues which should otherwise be generated through costly investments.

Moreover, the system (14-15) also implies that

$$
\frac{\partial k}{\partial c}=\frac{\partial y}{\partial q}=0
$$

which produces the following

Lemma 2 At any time t, the two RED efforts are independent of each other.

This result contradicts a strand of theoretical research illustrating the presence of either complementarity or substitutability between the two forms of innovation both in optimal control models describing a monopolist's problem (Lambertini and Mantovani, 2009) and in differential oligopoly games (Lambertini and Mantovani, 2010). ${ }^{9}$ The crucial difference between these models and the present one is that here demand is given and insensitive to the price level, while in the remainder of the literature on the same issue demand is a function of price. Hence, it seems that inelastic demand can be held responsible of the independence of R\&D efforts in the firm's portfolio. That is, when the total number of consumers queueing in front of its outlet

\footnotetext{
${ }^{9}$ For more on the emergence of complementarity or substitutability between process and product innovation, see Bhattacharya and Mookherjee (1986); Dasgupta and Maskin (1987); Lambertini (2003, 2004); and Lin (2004), inter alia.
} 
is fixed and does not react to any increase in quality or decrease in cost, the monopolist's innovation decision along either dimension is solely driven by time discounting and demand and cost parameters.

Imposing stationarity on states and controls yields the following set of solutions, where subscript $S S$ stands for steady state:

$$
\begin{gathered}
c_{S S}=q_{S S}=k_{S S}=y_{S S}=0 \\
c_{S S}=y_{S S}=0, k_{S S}=\delta, \\
q_{S S}=\frac{d(\Theta-1)-\sqrt{d^{2}(\Theta-1)^{2}-16 b v \delta \rho}}{4 v} \\
q_{S S}=\frac{d(\Theta-1)+\sqrt{d^{2}(\Theta-1)^{2}-16 b v \delta \rho}}{4 v} \\
c_{S S}=\frac{2 s \eta \rho}{d}, y_{S S}=\eta, k_{S S}=q_{S S}=0 \\
c_{S S}=\frac{2 s \eta \rho}{d}, y_{S S}=\eta, k_{S S}=\delta, \\
\frac{d(\Theta-1)-\sqrt{d^{2}(\Theta-1)^{2}-16 b v \delta \rho}}{4 v} \\
q_{S S}=\frac{2 s \eta \rho}{d}, y_{S S}=\eta, k_{S S}=\delta, \\
c_{S S}=\frac{2 s-1)+\sqrt{d^{2}(\Theta-1)^{2}-16 b v \delta \rho}}{4 v}
\end{gathered}
$$

Looking at solutions (18-19) and (21-22), it appears that the constraint

$$
d \geq \max \left\{1, \frac{4 \sqrt{b v \delta \rho}}{\Theta-1}\right\}
$$

must be satisfied in order for $q_{S S}$ to be real. If so, then it is easy to check that $q_{S S}$ is also positive. The stability properties are investigated in the next Section. 


\section{Stability analysis}

The stability properties of the dynamic model can be assessed looking at the Jacobian matrix of the state-control system made up by (3-4) and (14-15), which can be written as follows:

$$
\begin{aligned}
& J=\left[\begin{array}{llll}
\frac{\partial \dot{c}}{\partial c} & \frac{\partial \dot{c}}{\partial y} & \frac{\partial \dot{c}}{\partial q} & \frac{\partial \dot{c}}{\partial k} \\
\frac{\partial \dot{y}}{\partial c} & \frac{\partial \dot{y}}{\partial y} & \frac{\partial \dot{y}}{\partial q} & \frac{\partial \dot{y}}{\partial k} \\
\frac{\partial \dot{q}}{\partial c} & \frac{\partial \dot{q}}{\partial y} & \frac{\partial \dot{q}}{\partial q} & \frac{\partial \dot{q}}{\partial k} \\
\frac{\partial \dot{k}}{\partial c} & \frac{\partial \dot{k}}{\partial y} & \frac{\partial \dot{k}}{\partial q} & \frac{\partial \dot{k}}{\partial k}
\end{array}\right] \\
& =\left[\begin{array}{cccc}
\eta-y & -c & 0 & 0 \\
-\frac{d}{2 s} & \rho & 0 & 0 \\
0 & 0 & k-\delta & q \\
0 & 0 & \frac{4 v q-d(\Theta-1)}{2 b} & \rho
\end{array}\right]
\end{aligned}
$$

which is a block diagonal matrix, as a result of the fact that (i) the subsystem (3-14) is independent of $c$ and $y$ and, similarly, (ii) the system (4-15) is independent of $q$ and $k$. Hence, each $2 \times 2$ sub-matrix along the main diagonal of $(24)$ can be examined in isolation. Define these two submatrices, respectively, as

$$
J_{c, y}=\left[\begin{array}{cc}
\eta-y & -c \\
-\frac{d}{2 s} & \rho
\end{array}\right]
$$

and

$$
J_{q, k}=\left[\begin{array}{cc}
k-\delta & q \\
\frac{4 v q-d(\Theta-1)}{2 b} & \rho
\end{array}\right]
$$

Consider the point (17). There, we have that the traces and determinants of (25) and (26) are, respectively

$$
\begin{gathered}
\mathcal{T}\left(J_{c, y}\right)=\eta+\rho ; \Delta\left(J_{c, y}\right)=\eta \rho \\
\mathcal{T}\left(J_{q, k}\right)=\rho-\delta ; \Delta\left(J_{q, k}\right)=-\delta \rho
\end{gathered}
$$


so that instability arises along the marginal cost dimension.

In (18),

$$
\begin{gathered}
\mathcal{T}\left(J_{c, y}\right)=\eta+\rho ; \Delta\left(J_{c, y}\right)=\eta \rho \\
\mathcal{T}\left(J_{q, k}\right)=\rho ; \Delta\left(J_{q, k}\right)=\frac{\sqrt{\Omega}(d(\Theta-1)-\sqrt{\Omega})}{8 b v}
\end{gathered}
$$

where $\Omega \equiv d^{2}(\Theta-1)^{2}-16 b v \delta \rho \geq 0$ by virtue of $(23)$. Here, $\Delta\left(J_{c, y}\right)$ and $\Delta\left(J_{q, k}\right)$ are both positive and (18) is globally unstable.

In (19), we have

$$
\begin{gathered}
\mathcal{T}\left(J_{c, y}\right)=\eta+\rho ; \Delta\left(J_{c, y}\right)=\eta \rho \\
\mathcal{T}\left(J_{q, k}\right)=\rho ; \Delta\left(J_{q, k}\right)=-\frac{\sqrt{\Omega}(d(\Theta-1)+\sqrt{\Omega})}{8 b v}
\end{gathered}
$$

so that again the marginal cost side of the system is affected by instability.

In (20), the traces and determinants are

$$
\begin{gathered}
\mathcal{T}\left(J_{c, y}\right)=\rho ; \Delta\left(J_{c, y}\right)=-\eta \rho \\
\mathcal{T}\left(J_{q, k}\right)=\rho-\delta ; \Delta\left(J_{q, k}\right)=-\delta \rho
\end{gathered}
$$

Hence, in principle, (20) is a saddle point. However, it can be disregarded as economically inadmissible, as it involves that product quality is nil. This, looking at the utility function of a generic consumer, implies that the latter's ability to pay $\theta q$ is also nil, and consequently the monopolist's price and revenues would be equal to zero.

We are left with (21) and (22). In (21), we have

$$
\begin{gathered}
\mathcal{T}\left(J_{c, y}\right)=\rho ; \Delta\left(J_{c, y}\right)=-\eta \rho \\
\mathcal{T}\left(J_{q, k}\right)=\rho ; \Delta\left(J_{q, k}\right)=\frac{\sqrt{\Omega}(d(\Theta-1)-\sqrt{\Omega})}{8 b v}
\end{gathered}
$$

which reveals that the dimension of product quality is affected by instability. Finally, in (22), we have

$$
\begin{gathered}
\mathcal{T}\left(J_{c, y}\right)=\rho ; \Delta\left(J_{c, y}\right)=-\eta \rho \\
\mathcal{T}\left(J_{q, k}\right)=\rho ; \Delta\left(J_{q, k}\right)=-\frac{\sqrt{\Omega}(d(\Theta-1)+\sqrt{\Omega})}{8 b v}
\end{gathered}
$$

in which both determinants are negative. Accordingly, we may formulate: 
Proposition 3 In the parameter region identified by

$$
d \geq \max \{1,4 \sqrt{b v \delta \rho} /(\Theta-1)\}
$$

the dynamic monopoly model with a bidimensional RED portfolio produces a unique saddle point equilibrium at

$$
\begin{gathered}
c_{S S}^{m}=\frac{2 s \eta \rho}{d}, y_{S S}^{m}=\eta, k_{S S}^{m}=\delta, \\
q_{S S}^{m}=\frac{d(\Theta-1)+\sqrt{d^{2}(\Theta-1)^{2}-16 b v \delta \rho}}{4 v}
\end{gathered}
$$

\section{$5 \quad$ Welfare appraisal}

To complement the analysis, one can look at the welfare consequences of the firm's R\&D decisions. In the remainder of the analysis illustrated in this Section, we will examine a situation in which, under the monopoly pricing rule $p^{m}=(\Theta-1) q$, a benevolent social planner is in charge of choosing the investment path for process and product innovation to maximise the intertemporal flow of social welfare discounted at the same rate $\rho$ used by the monopolist. This approach to the assessment of the (in)efficiency of the monopolist's R\&D choices is in line with Spence's (1975) original appraisal of quality supply in monopoly in a static model.

Define the instantaneous social welfare function as $S W=\pi+C S$, with

$$
C S=\int_{\Theta-1}^{\Theta}(\theta q-p) d \theta=\frac{q}{2}
$$

measuring consumer surplus. Since instantaneous profits are (5), the social welfare function is

$$
S W=\frac{q[1+2 d(\Theta-1)-2 v q]}{2}-c d-b k^{2}-s y^{2}
$$

The planner's Hamiltonian function is therefore

$$
\mathcal{H}^{s p}=e^{-\rho t}\left(S W+\lambda^{s p} \dot{q}+\mu^{s p} \dot{c}\right)
$$

where the superscript $s p$ mnemonics for social planning. The FOCs on R\&D controls $k$ and $y$ coincide with (8-9), and the costate equation concerning the 
dynamics of $\mu$ is the same as in (11). However, the presence of consumer surplus in the instantaneous payoff entails that the remaining costate equation is indeed different from (10):

$$
\dot{\lambda^{s p}}=(\delta+\rho-k) \lambda^{s p}-d(\Theta-1)+2 v q-\frac{1}{2}
$$

As a result, the planner's control equations are

$$
\begin{aligned}
& \dot{k^{s p}}=\rho k^{s p}-\frac{q[1+2 d(\Theta-1)-4 v q]}{2 b} \\
& \dot{y^{s p}}=\rho y^{s p}-\frac{c d}{2 s}
\end{aligned}
$$

The above system reveals that the planner's incentive to abate marginal production cost $c$ is indeed the same as the profit-maximising monopolist's (and therefore the investment in process innovation by the latter is socially efficient), while imposing stationarity on (43) delivers

$$
k_{S S}^{s p}=\frac{\left[1+2 d(\Theta-1)-4 v q_{S S}\right] q_{S S}}{4 b \rho}
$$

which can be compared with the monopoly solution attained by imposing stationarity on (14):

$$
k_{S S}^{m}=\frac{\left[(\Theta-1) d-2 v q_{S S}\right] q_{S S}}{2 b \rho}
$$

The difference between $k_{S S}^{s p}$ and $k_{S S}^{m}$ is

$$
k_{S S}^{s p}-k_{S S}^{m}=\frac{q_{S S}}{4 b \rho}>0
$$

for any $q_{S S}>0$, in particular at the quality level $q_{S S}^{m}$ reached by the monopolist in the steady state driven by profit incentives only. An analogous exercise can be executed imposing $k=k_{S S}^{s p}$ and $q=q_{S S}^{m}$ and then observing that the state equation of product quality simplifies as follows:

$$
\dot{q}=\frac{[d(\Theta-1)+\sqrt{\Omega}]^{2}}{64 b v^{2} \rho}>0
$$

which lends itself to the same interpretation. This translates into the following: 
Proposition 4 Given the monopoly pricing rule, profit incentives cause a downward distortion of the steady state quality level. Process innovation incentives are instead the same under both regimes.

The driving force of quality undersupply at the monopoly equilibrium has to be identified in the absence of consumer surplus in the firm's objective: a benevolent social planner would welcome any increase in $q$ to benefit consumers, given the monopoly price and the corresponding (socially efficient) amount of cost-reducing $\mathrm{R} \& \mathrm{D}$ chosen by the firm. This amounts to saying that, at the monopoly optimum, consumer surplus is still increasing in product quality. This reproduces in a dynamic setup a result dating back to Spence (1975) and Mussa and Rosen (1978). Conversely, process innovation is socially efficient: this depends on the fact that $p^{m}$ is not a function of marginal cost and market demand is not sensitive to any decrease in the latter. As a result, underinvesting in process innovation would simply cause a decrease in profits (gross of all fixed costs). For this reason, it is in the best interest of the profit-maximising monopolist not to distort this dimension of its investment portfolio.

\section{Concluding remarks}

We have characterised the optimal R\&D portfolio of a monopolist, showing that product improvement and cost abatement are independent of each other and both respond negatively to any increase in demand. Equilibrium quality falls short of the socially optimal level, while marginal cost reduction is socially efficient.

\section{References}

[1] Bhattacharya, S. and D. Mookherjee (1986). Portfolio choice in research and development. RAND Journal of Economics, 17, 594-605.

[2] Besanko, D., S. Donnenfeld and L. White (1987). Monopoly and quality distortion: effects and remedies. Quarterly Journal of Economics, 102, 743-768.

[3] Champsaur, P. and J.-C. Rochet (1989). Multiproduct duopolists. Econometrica, 57, 533-557. 
[4] Colombo, L. and L. Lambertini (2003). Dynamic advertising under vertical product differentiation. Journal of Optimization Theory and Applications, 119, 261-280.

[5] Dasgupta, P. and E. Maskin (1987). The simple economics of research portfolios. Economic Journal, 97, 581-595.

[6] Dockner, E.J. (1985). Local stability analysis in optimal control problem with two state variables, in G. Feichtinger (ed.), Optimal Control Theory and Economic Analysis, vol. 2, Amsterdam, North-Holland, 89-103.

[7] Dockner, E.J. and G. Feichtinger (1991). On the optimality of limit cycles in dynamic economic systems. Journal of Economics, 53, 31-50.

[8] El Ouardighi, F. and B. Kim (2010). Supply quality management with wholesale price and revenue-sharing contracts under horizontal competition. European Journal of Operational Research, 206, 329-340.

[9] El Ouardighi, F. and K. Kogan (2013). Dynamic conformance and design quality in a supply chain: an assessment of contracts' coordinating power, Annals of Operations Research, 211, 137-166.

[10] Feichtinger, G., R.F. Hartl and S.P. Sethi (1994). Dynamic optimal control models in advertising: recent developments. Management Science, 40, 195-226.

[11] Gabszewicz, J.J. and J.-F. Thisse (1979). Price competition, quality and income disparities. Journal of Economic Theory, 20, 340-359.

[12] Itoh, M. (1983). Monopoly, product differentiation and economic welfare. Journal of Economic Theory, 31, 88-104.

[13] Kotowitz, Y. and F. Mathewson (1979). Advertising, consumer information, and product quality. Bell Journal of Economics, 10, 566-588.

[14] Lambertini, L. (1997). The multiproduct monopolist under vertical differentiation: an inductive approach. Recherches Economiques de Louvain, 63, 109-122.

[15] Lambertini, L. (2003). The monopolist's optimal R\&D portfolio. Oxford Economic Papers, 55, 561-578. 
[16] Lambertini, L. (2004). Process and product R\&D by a multiproduct monopolist: a reply to Lin. Oxford Economic Papers, 56, 745-749.

[17] Lambertini, L. (2006). The Economics of Vertically Differentiated Markets, Cheltenham, Edward Elgar.

[18] Lambertini, L. and A. Mantovani (2009). Process and product innovation by a multiproduct monopolist: a dynamic approach. International Journal of Industrial Organization, 27, 508-518.

[19] Lambertini, L. and A. Mantovani (2010). Process and product innovation: a differential game approach to product life cycle. International Journal of Economic Theory, 6, 227-252.

[20] Lambertini, L. and R. Orsini (2000). Process and product innovation in a vertically differentiated monopoly. Economics Letters, 68, 333-337.

[21] Lin, P. (2004). Process and product R\&D by a multiproduct monopolist. Oxford Economic Papers, 56, 735-743.

[22] Maskin, E. and J. Riley (1984). Monopoly with incomplete information, RAND Journal of Economics, 15, 171-196.

[23] Mussa, M. and S. Rosen (1978). Monopoly and product quality. Journal of Economic Theory, 18, 301-317.

[24] Shaked, A. and J. Sutton (1982). Relaxing price competition through product differentiation. Review of Economic Studies, 49, 3-13.

[25] Singh, N. and X. Vives (1984). Price and quantity competition in a differentiated duopoly. RAND Journal of Economics, 15, 546-554.

[26] Spence, A.M. (1975). Monopoly, quality and regulation. Bell Journal of Economics, 6, 417-429. 